\title{
Derived and thiourea-functionalized silica for cadmium removal: isotherm, kinetic and thermodynamic studies
}

\author{
Iyanu Omotunde ${ }^{1} \cdot$ Afamefuna Okoronkwo $^{1} \cdot$ Olugbenga Oluwashina $^{1}$
}

Received: 1 June 2015 / Accepted: 27 December 2017 / Published online: 24 January 2018

(C) The Author(s) 2018. This article is an open access publication

\begin{abstract}
The present study explored the feasibility of using derived and thiourea-functionalized silica as adsorbent for the removal of cadmium under different experimental conditions. Effects of various parameters such as function of point of zero charge $\left(\mathrm{pH}_{\mathrm{PZC}}\right)$, solution $\mathrm{pH}$, sorbent-sorbate resident time and ratio, concentration and temperature were investigated. The sorption of cadmium followed the pseudo-second-order rate kinetics. Thermodynamic studies revealed that the sorption of cadmium was endothermic and spontaneous, with good affinity toward the sorbent. Various isotherm models, viz. Langmuir, Freundlich, Temkin, Dubinin-Radushkevich, Harkins-Jura, and Halsey isotherms were used to analyze the equilibrium data at different temperatures. The Freundlich, Halsey, Langmuir, and Temkin models were found to be in good agreement with the experimental data with high $R^{2}$, low RMSE, and low $\chi^{2}$ values. The results show that the sorption capacity increases with an increase in solution temperature from 28 to $65^{\circ} \mathrm{C}$. The maximum sorption capacity calculated from Langmuir isotherm was 27.55 and $28.41 \mathrm{mg} \mathrm{g}^{-1}$ for derived and thiourea-functionalized silica, respectively, at optimum condition of $\mathrm{pH} 5$ and contact time of $120 \mathrm{~min}$.
\end{abstract}

Keywords Cadmium $\cdot$ Silica $\cdot$ Isotherm $\cdot$ Functionalization $\cdot$ Thiourea $\cdot$ Endothermic

\section{Introduction}

Surface and ground water contamination caused by anthropogenic pollutants has been recorded as a major problem in the global context (Satya et al. 2011). Thousands of chemicals are emptied directly and indirectly into water bodies every day without further treatment for elimination of the included noxious compounds (Salim et al. 2008). The presence of heavy metals in the aqueous environment has potentially damaging effects on human physiology and other biological systems when the levels are exceeding high (Hua et al. 2012). Cadmium is a toxic heavy metal of significant environmental and occupational concern. It has been released to the environment through the combustion of fossil fuels, metal production, application of phosphate fertilizers, electroplating, and the manufacturing of batteries, pigments, and screens (Sharma 2008). Adsorption, among other technologies used for waste water treatment, has been

Afamefuna Okoronkwo

afamex13@gmail.com

1 Department of Chemistry, The Federal University of Technology, P.M.B 704, Akure, Nigeria proven to be economical and efficient for removing heavy metals, organic pollutants and dyes from polluted water (Tangjuank et al. 2009). Of all the numerous adsorbents, silica has attracted great attention for its excellent chemical stability, good adsorption or cation exchange capability, and rationally modifiable surface (Piao et al. 2008; Khosravan 2009). The large surface area and pore volume of silica underlie facile adsorption and high loading effect of various chelating agents (Trewyn et al. 2007). Silica gel especially immobilized with various organic compounds with metal chelating ability had been widely used (Zaporozhets et al. 1999), because this support offers pronounced advantages over other organic/inorganic support (Arakaki et al. 2000). The application of silica is attributed to the presence of high number of reactive hydroxylic groups on its surface. These groups enable bonding of organic molecules which contain Lewis bases that can coordinate metal ions in solution, hence increasing metal ions sorption (Tzvetkova and Nickolov 2012). The addition of organic groups by the grafting of organosiloxane precursors onto the surface of the pores, results in functional mesoporous hybrid materials (Lee and Yi 2001; Zhang et al. 2007). These organic-inorganic hybrid materials have been reported to exhibit improved sorption 
properties toward heavy metal ions (Liu et al. 2000; Walkarius et al. 2002). Functionalization confers on the adsorbent unique properties with the presence of electron donor atoms such as nitrogen, sulfur and oxygen.

Several kinds of silica have been functionalized with different ligands and used for heavy metal removal from water. The modifications of SBA-15, SBA-117 and MCM-41 with 2-mercaptothiazoline, 2-mercaptobenzothiazole, 3-aminothiazole, MCM-48 with benzoyl thiourea have been reported (Perez-Quintanilla et al. 2006; Lee et al. 2001; Walcarius et al. 2003; Tzvetkova and Nickolov. 2012). In all these experiments, the silica used is majorly synthetic in nature. The purpose of this work is to derive silica gel from agricultural waste products (maize husk and maize stem ash) and functionalize with thiourea, expecting selectivity toward $\mathrm{Cd}(\mathrm{II})$ sorption. The properties examined will be compared to those of the unmodified silica gel.

\section{Experimental}

\section{Material preparation}

Maize husks and maize stems used for this research work were obtained from south western Nigeria, after the harvest season. The maize husks and stems were washed and sun dried. Combustion was carried out at $650{ }^{\circ} \mathrm{C}$ for $3 \mathrm{~h}$ at a heating rate of $10^{\circ} \mathrm{C} \mathrm{min}-1$ in a muffle furnace, and left over night to cool in the furnace.

\section{Silica extraction}

Silica was extracted from maize husk ash and maize stem ash, adapting the method of Kamath and Proctor (1998), $250 \mathrm{~mL}$ portions of $1 \mathrm{~N} \mathrm{NaOH}$ were added to $50 \mathrm{~g}$ of the ash samples and boiled in covered $500 \mathrm{~mL}$ Erlenmeyer flask for $1 \mathrm{~h}$ with constant stirring. The solutions were filtered through a Whatman no. 41 ashless filter paper. The filtrate was allowed to cool and the $\mathrm{pH}$ was reduced with $3 \mathrm{~N} \mathrm{HCl}$ to 7.0 with constant stirring and incubated to promote gel formation. The formed gel was aged for $18 \mathrm{~h}$. The soft gel was broken and the slurry was centrifuged at $4000 \mathrm{rpm}$ for $5 \mathrm{~min}$. The supernatant was discarded and the gels transferred into a beaker and dried at $80{ }^{\circ} \mathrm{C}$ for $24 \mathrm{~h}$ to produce xerogels. The xerogels were subjected to additional washing with deionized water to effectively remove minerals and impurity from the silica.

\section{Silica functionalization}

In the preparation of thiourea-functionalized silica, the derived silica was first acid treated to activate the surface silanol $(\mathrm{Si}-\mathrm{OH})$ groups. $10 \mathrm{~g}$ of silica was added to
$100 \mathrm{~mL}$ of deionized distilled water and the solution $\mathrm{pH}$ was adjusted to 4.0 using $0.1 \mathrm{~N}$ nitric acid. The mixture was heated $\left(50-60{ }^{\circ} \mathrm{C}\right)$ with continuous stirring for $3 \mathrm{~h}$. Silica was separated by filtering the mixture using Whatman no. 41 ashless filter paper. The silica cake was washed with $25 \mathrm{~mL}$ of deionized distilled water twice and then heated in an oven at $120^{\circ} \mathrm{C}$ for $8-12 \mathrm{~h}$. The dried silica was used for further silanization. A dry phase deposition method was used to functionalize the silica particles. The particles were dispersed in anhydrous ethanol $(15 \mathrm{~mL}$ of ethanol per gram of silica) and thiourea was dissolved such that the ratio of the amount of silica (in $\mathrm{g}$ ) to the amount of thiourea was $7: 3$. Ultra high purity grade nitrogen was bubbled through the mixture to evaporate the ethanol under fume hood, thus depositing thiol $-\mathrm{SH}$ on the surface of the silica. For the silanization reaction, the silica was then placed in oven at $120{ }^{\circ} \mathrm{C}$ for $8-10 \mathrm{~h}$. The material was allowed to cool and washed twice with $50 \mathrm{~mL}$ of anhydrous ethanol to remove any physically adsorbed thiourea and dried again in an oven.

\section{Batch adsorption experiment}

Batch experiments were conducted to generate $\mathrm{pH}$-based plots by adding $25 \mathrm{mg}$ of the prepared samples to $20 \mathrm{~mL}$ of $100 \mathrm{mg} \mathrm{L}^{-1}$ cadmium solution. The experiments were performed at $\mathrm{pH}$ values where metal hydroxide precipitation is not expected to occur. The effect of contact time was studied at various time intervals and residual $\mathrm{Cd}(\mathrm{II})$ were analyzed.

Equilibrium adsorption of $\mathrm{Cd}(\mathrm{II})$ ion on the prepared samples was carried out using $20 \mathrm{~mL}$ of various concentrations $\left(25-500 \mathrm{mg} \mathrm{L}^{-1}\right)$ of metal ions at constant metal ion-substrate contact time $(2 \mathrm{~h})$ at different temperature intervals $\left(28-65{ }^{\circ} \mathrm{C}\right.$ ) and at a predetermined $\mathrm{pH}$ of 5 . At the end of the given contact time, the mixture was filtered rapidly. The metal ion concentration in the filtrate was determined by atomic absorption spectrometer model 200A. The amount of metal ion adsorbed by the prepared samples was obtained as the difference between the initial and final ion concentration of the solutions.

\section{Characterization of the adsorbents}

Fourier transform infrared spectrometry (PerkinElmer FTIR$\mathrm{RX} 1$ ) with $\mathrm{KBr}$ pellets was used to study the functional groups available on the surface of the adsorbents. Scanning electron microscopic analyses of the adsorbents studied were conducted using Philips XL30 FEG to characterize the surface morphology of the adsorbents.

The point of zero surface charge $\left(\mathrm{pH}_{\mathrm{PZC}}\right)$ characteristics of the adsorbents was determined using the solid addition method (Balistrier and Murray 1981), viz to a series of $100 \mathrm{~mL}$ conical flask, $45 \mathrm{~mL}$ of $0.1 \mathrm{M} \mathrm{KNO}_{3}$ was transferred. The $\mathrm{pHs}$ of the solution were adjusted from 1 to 10 
by adding either $0.1 \mathrm{~N} \mathrm{HNO}_{3}$ or $\mathrm{NaOH}$. The total volume of the solution in each flask was made exactly to $50 \mathrm{~mL}$ by adding $0.1 \mathrm{M} \mathrm{KNO}_{3}$ solution of the same strength. The $\mathrm{pH}_{\mathrm{i}}$ of the solution was then accurately noted and $0.1 \mathrm{~g}$ of the adsorbent was added to each flask, which were securely capped immediately. The suspension was allowed to equilibrate for $24 \mathrm{~h}$ with intermittent manual shaking. The final $\mathrm{pH}$ values of the supernatant liquid $\left(\mathrm{pH}_{\mathrm{f}}\right)$ were noted. The difference between the initial and the final $\mathrm{pH}$ $(\Delta \mathrm{pH})$ values was plotted against the initial $\mathrm{pH}$. The point of intersection of the resulting curves, at which $\mathrm{pH}$ value was zero, gave the $\mathrm{pH}_{\mathrm{PZC}}$.

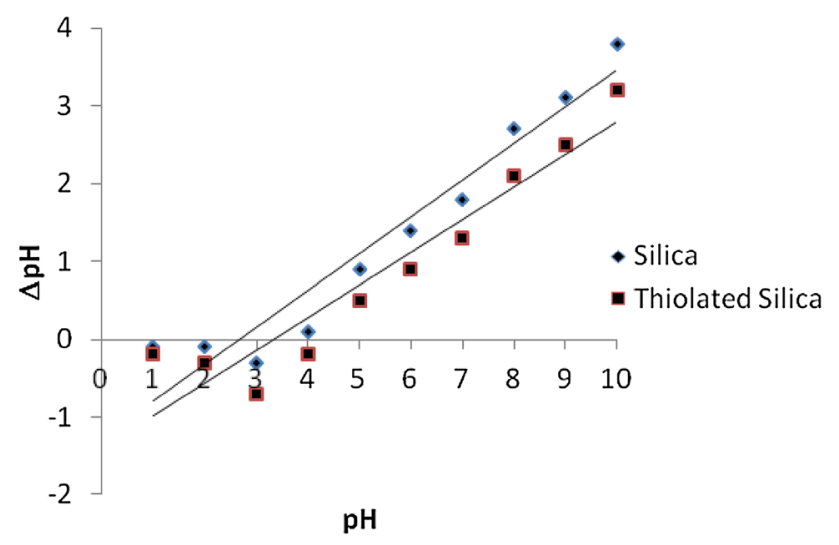

Fig. 1 Point of zero charge of the adsorbents

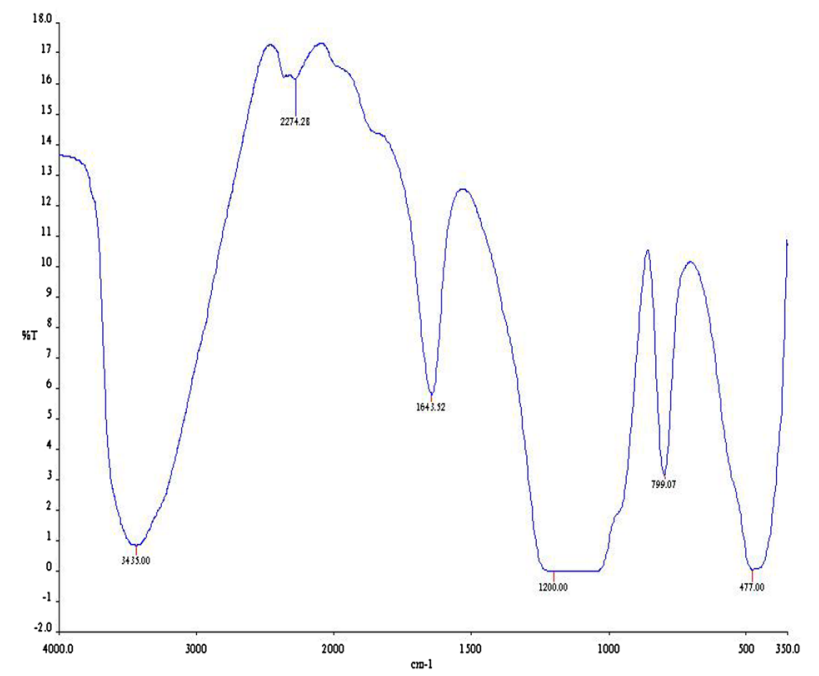

(a)

\section{Results and discussion}

\section{Characterization of the adsorbents}

The physical characterization of derived and thiol-functionalized silica indicated that the point of zero charge (PZC) value was around 3.8 and 4.3, respectively. To understand the adsorption mechanism and the influence of $\mathrm{pH}$ on heavy metal removal, it is necessary to determine the point of zero charge $\left(\mathrm{pH}_{\mathrm{PZC}}\right)$ of the sorbent. Sorption of cations is favored at $\mathrm{pH}>\mathrm{pH}_{\mathrm{PZC}}$, while the sorption of anions is favored at $\mathrm{pH}<\mathrm{pH}_{\text {PZC }}$. The plots of PZC (Fig. 1) indicated that at $\mathrm{pH}$ below 3.8 and 4.3 for both derived and thiol-functionalized silica, respectively, the surface of the adsorbents is predominated by positive charges, which resulted in low uptake of $\mathrm{Cd}$ ion, while a $\mathrm{pH}$ greater than 3.8 and 4.3 for derived and thiol-functionalized silica, respectively, the surface is predominated by negative charges, resulting in high uptake of positively charged $\mathrm{Cd}$ ion. The information obtained from the $\mathrm{pH}_{\mathrm{PZC}}$ determination explains the sudden increase in percentage removal observed around $\mathrm{pH}$ of 5 for both adsorption studies.

To verify the successful functionalization of the derived silica with thiourea, FTIR spectra of the non-functionalized silica and the thiol-functionalized silica were obtained and compared (Plate 1). The silica materials exhibited associated water even after drying. In addition, both adsorbents showed the presence of silanol groups $(\mathrm{Si}-\mathrm{OH})$ at surface. These groups correspond to the absorbance bands at $3435,1643.52$ and $968 \mathrm{~cm}^{-1}$ for derived silica and 3375 and $959.84 \mathrm{~cm}^{-1}$ for thiol-functionalized silica. These bands assigned are due to the interactions

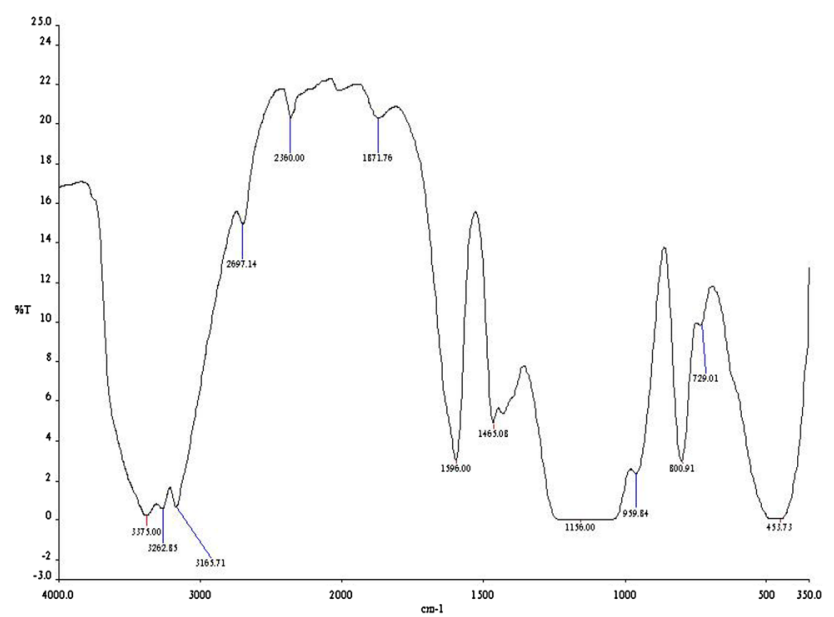

(b)

Plate 1 FTIR spectra a derived silica and $\mathbf{b}$ thiol-functionalized silica 
between hydroxyl groups on silica surface and water present in the surrounding atmosphere (Al-Owein and El-Rassy 2009). The bands at 1200, 799.07 and $477 \mathrm{~cm}^{-1}$ for silica and 1156 , 800.91 and $453.73 \mathrm{~cm}^{-1}$ for functionalized silica were due to $\mathrm{Si}-\mathrm{O}-\mathrm{Si}$ antisymmetric stretching, symmetric stretching and bending vibrations, respectively, of the siloxane groups (AlOwein and El-Rassy 2009, Socrates 1994). The presence of the thiol groups (-SH) was observed in the band at $2697.14 \mathrm{~cm}^{-1}$ for the functionalized silica. Also, the FTIR spectra of functionalized silica showed a characteristic absorption band at $1596 \mathrm{~cm}^{-1}$ which can be assigned to a weak N-H bending attributed to the modifying agent (thiourea).

The SEM images (Plate 2) showed the irregular texture and porous nature of the surface of the adsorbent. The seemingly rough surface and porosity of the adsorbent is an indication of high surface area which can promote the adherence of cadmium. Thiol-functionalization appears to have resulted in changes in the chemistry of the surface and affect the surface area development and pore structure of the sample compared to the unmodified.

The ion-exchange reaction on the derived silica gel (Eq. 1) and thiol-functionalized silica gel surface (Eqs. 2, 3) are accomplished through the substitution of protons of the surface silanol and modified silanol groups by the metal solution as follows:

$\mathrm{Cd}^{2+}+x(-\mathrm{SiOH}) \leftrightarrow \mathrm{Cd}(-\mathrm{SiO})_{x}^{(2-n)+}+x \mathrm{H}^{+}$,

$\mathrm{Cd}^{2+}+[\mathrm{SH}]$ (on the surface) $\leftrightarrow\left[\mathrm{Cd}^{2+} \mathrm{SH}\right]$ (on the surface).

$\mathrm{Cd}^{2+}+2 \mathrm{SH}$ (on the surface) $\leftrightarrow \mathrm{Cd}^{2+} \bigsqcup_{\mathrm{SH} \text { (on the surface) }}^{\mathrm{SH} \text { (on the surface) }}$

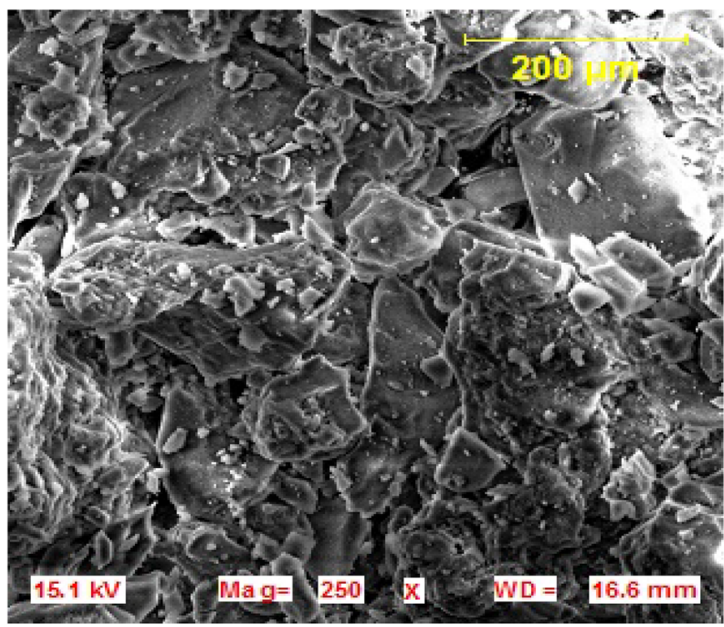

(a)
This has been empirically proved in various studies on the adsorption of metal ions by silica gel (Stanton and Maatman 1963; Allen and Matijevic 1970).

\section{Effect of contact time on adsorption}

The effect of contact time on the adsorption of cadmium ion on derived and thiol-functionalized silica was investigated to determine the minimum necessary time to achieve the sorption equilibrium. Figure 2 shows the adsorption time curve of cadmium ion on derived and thiol-functionalized silica at the initial concentration of $100 \mathrm{mg} \mathrm{L}^{-1}$ and at room temperature. The rate of sorption of cadmium ion was rapid during the first $60 \mathrm{~min}$ and attaining equilibrium at $120 \mathrm{~min}$. The percentage uptake of cadmium ions on both the derived and thiol-functionalized silica after 360 min was 77 and 98\%, respectively.

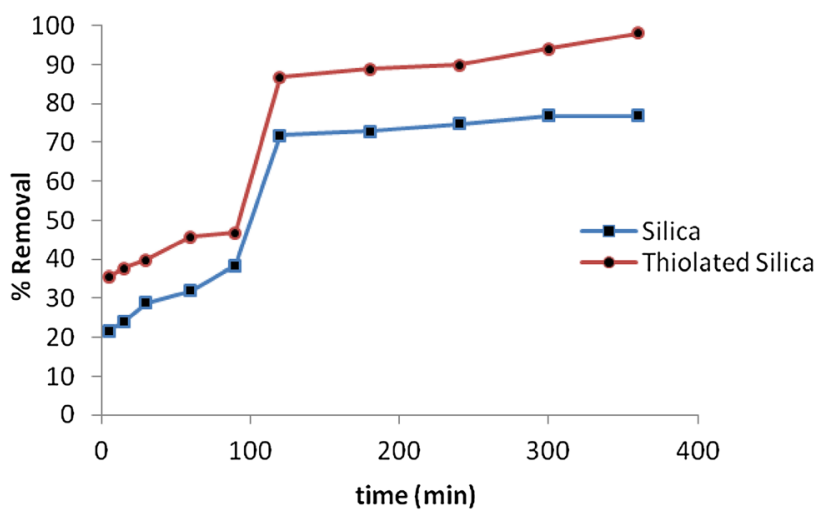

Fig. 2 Effect of contact time on equilibrium cadmium removal

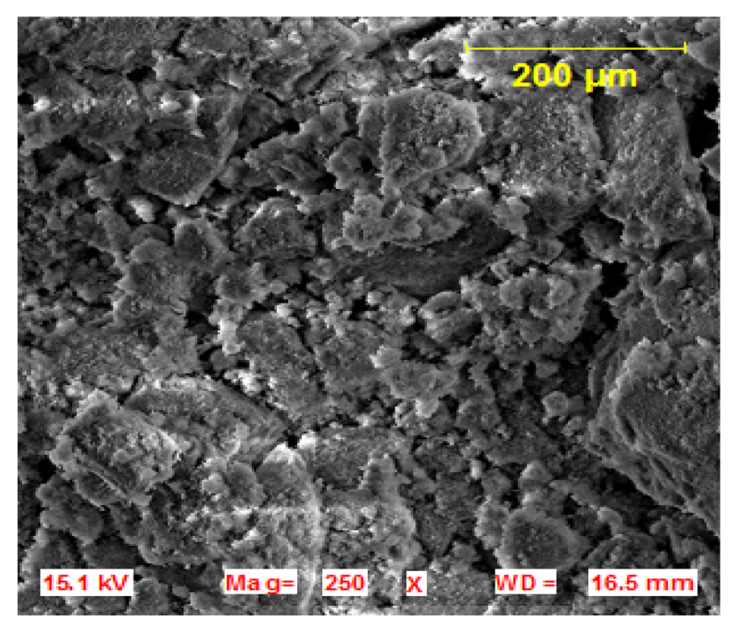

(b)

Plate 2 SEM images of $\mathbf{a}$ derived silica and $\mathbf{b}$ thiol-functionalized silica 
This behavior suggests that at the initial stage, sorption takes place rapidly due to the accumulation of $\mathrm{Cd}$ ions on the surface and the availability of abundant active sites on the surface of the adsorbent. The adsorption process slows down with time as the active sites are used up and the remaining vacant surface sites are difficult to be occupied by $\mathrm{Cd}$ ions due to the formation of repulsive forces between the $\mathrm{Cd}$ on the solid surface and the liquid phase.

\section{Effect of initial metal concentration on adsorption}

The effect of initial metal concentration of cadmium ion for maximum uptake was studied between the concentration ranges of $25-500 \mathrm{mg} \mathrm{L}^{-1}$. These studies were carried out at different temperatures ranging from 28 to $65^{\circ} \mathrm{C}$. As the concentration of $\mathrm{Cd}$ ion was increased from 25 to $500 \mathrm{mg} \mathrm{L}^{-1}$, the percentage of adsorption decreased and this was the same at the different temperature ranges used. The percentage of adsorption of $\mathrm{Cd}$ ion onto derived silica was found to decrease from 84.9 to $45.9 \%$ and for thiol-functionalized silica; percentage of adsorption was decreased from 91.33 to $51.2 \%$. This was due to the increase in concentration of $\mathrm{Cd}$ ions for lesser number of adsorption sites and the saturation of active sites with $\mathrm{Cd}$ molecules. The equilibrium uptake and adsorption yield were highest for thiol-functionalized silica, which was expected because of the greater specific surface area and the microporous structure of thiol-functionalized silica compared with derived silica.

\section{Effect of pH on adsorption}

$\mathrm{pH}$ is one of the most important factors controlling the adsorption of heavy metal ion onto adsorbent particles. $\mathrm{pH}$ affects the surface charge of the adsorbents as well as the degree of ionization and speciation of adsorbate during the adsorption process. The effect of solution $\mathrm{pH}$ on the adsorption of cadmium ion was carried out at different $\mathrm{pH}$ values ranging from 1 to 7 (Fig. 3) at the initial concentration of $100 \mathrm{mg} \mathrm{L}^{-1}$ and at room temperature. The cadmium percentage removal was found to increase with an increase in $\mathrm{pH}$ from 1 to 5. The maximum uptake capacity of 77 and $94 \%$ for derived and thiol-functionalized silica were obtained and pH 5 and then decreased with further increase in the solution $\mathrm{pH}$.

The effect of $\mathrm{pH}$ can be explained considering the surface charge on the adsorbent material. At low $\mathrm{pH}$, the solution is highly acidic, due to high positive charge density the electrostatic repulsion will be high, resulting in lower uptake of positively charged metal ions. Also, the protonation of the active sites on the adsorbents reduces the number of negatively charged sites available for cadmium ions to bind; hence a decrease in adsorption. As the $\mathrm{pH}$ of the solution increased, the active sites become deprotonated and free for

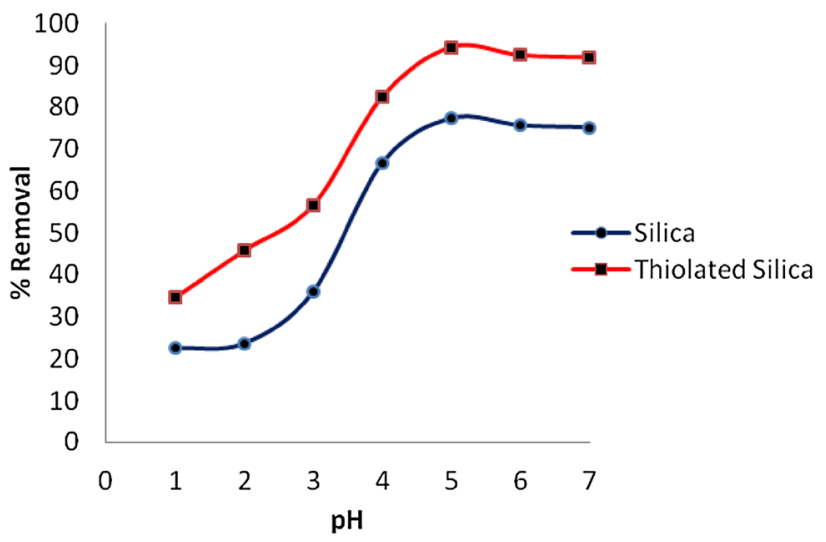

Fig. 3 Effect of $\mathrm{pH}$ on cadmium removal

cadmium ions to bind. This reduces the competition between metal ions and protons leading to an increase in adsorption with increase in $\mathrm{pH}$. Also, it results in a lower electrostatic repulsion between the surface and the metal ions and hence uptake of metal ions increases (Rezvani-Boroujeni et al. 2017). This description is supported by the $\mathrm{pH}_{\mathrm{PZC}}$ values of the adsorbent, indicating that the surface became negative above the PZC values, which facilitated the attraction of positively charged ions $\left(\mathrm{Cd}^{2+}\right)$ to the negative adsorbents surface.

\section{Adsorption kinetics}

Kinetics is one of the major approaches used to evaluate adsorption dynamics. Kinetic constants can be used to optimize the residence time of adsorption process. To examine the controlling mechanism of the adsorption process, various kinetic models were used to test the experimental data; pseudo-first-order and pseudo-second-order kinetic models and Elovich model were applied to the kinetic data. The conformity between the experimental data and the modelpredicted values was expressed by coefficients of determination $\left(R^{2}\right)$.

The rate constant of adsorption was determined from pseudo-first-order rate expression given in Eq. 4,

$\log \left(q_{\mathrm{e}}-q_{t}\right)=\log q_{\mathrm{e}}-\left(k_{1} / 2.303\right) t$,

where $q_{\mathrm{e}}$ and $q_{t}$ are the amount of $\mathrm{Cd}$ absorbed at equilibrium and at time $(t)\left(\mathrm{mg} \mathrm{g}^{-1}\right)$, respectively, and $k_{1}\left(\mathrm{~min}^{-1}\right)$ is the rate constant of adsorption. The values of the $k_{1}$ and $q_{\mathrm{e}, \mathrm{cal}}$ were calculated from the slope and the intercept of the plot of $\log \left(q_{\mathrm{e}}-q_{\mathrm{t}}\right)$ versus $t$ (Fig. 4a) and reported in Table 1 . Results presented show that there is a large difference in the value of $q_{\mathrm{e} \text {,cal }}$ and $q_{\mathrm{e}, \mathrm{exp}}$ and $R^{2}$ are not close to unity for the two adsorbents. It can be concluded that the pseudo-firstorder model was not suitable to describe the kinetic profile of the adsorption.

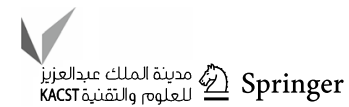




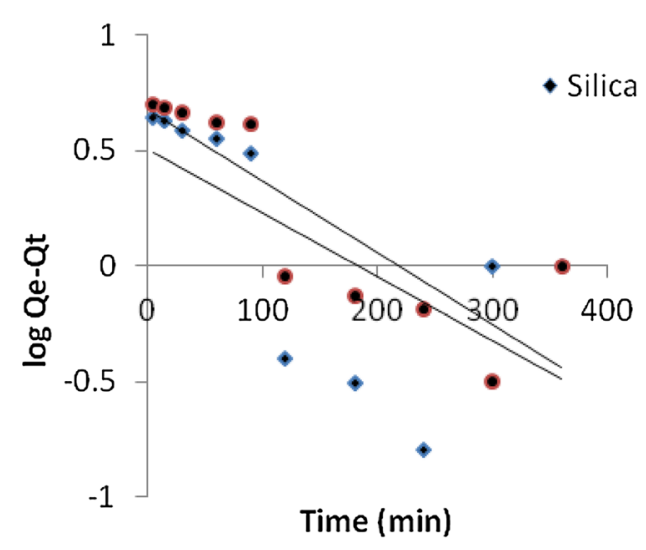

(a)

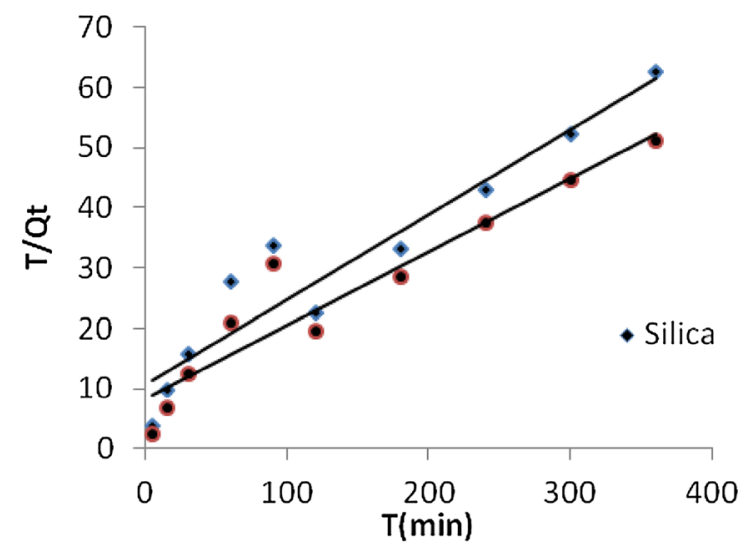

(b)

Fig. 4 Kinetic plot for a pseudo-first-order model and $\mathbf{b}$ pseudo-second order model

Table 1 Kinetic parameters for adsorption on cadmium ions

\begin{tabular}{|c|c|c|}
\hline Parameters & Derived silica & $\begin{array}{l}\text { Thiol-func- } \\
\text { tionalized } \\
\text { silica }\end{array}$ \\
\hline \multicolumn{3}{|l|}{ Pseudo-first-order } \\
\hline$q_{\mathrm{e}} \exp \left(\mathrm{mg} \mathrm{g}^{-1}\right)$ & 5.74 & 7.04 \\
\hline$q_{\mathrm{e}, \mathrm{cal}}\left(\mathrm{mg} \mathrm{g}^{-1}\right)$ & 3.22 & 4.74 \\
\hline$k_{1}\left(\min ^{-1}\right)$ & 0.0064 & 0.0071 \\
\hline$R^{2}$ & 0.4160 & 0.7191 \\
\hline \multicolumn{3}{|l|}{ Pseudo-second-order } \\
\hline$q_{\mathrm{e}, \mathrm{cal}}\left(\mathrm{mg} \mathrm{g}^{-1}\right)$ & 7.06 & 8.22 \\
\hline$k_{2}\left(\mathrm{~g} \mathrm{mg}^{-1} \min ^{-1}\right)$ & 0.0019 & 0.0018 \\
\hline$h\left(\mathrm{mg} \mathrm{g}^{-1} \min ^{-1}\right)$ & 0.095 & 0.118 \\
\hline$R^{2}$ & 0.9071 & 0.9023 \\
\hline \multicolumn{3}{|l|}{ Elovich model } \\
\hline$A_{\mathrm{E}}\left(\mathrm{g} \mathrm{mg}^{-1}\right)$ & 0.79 & 0.73 \\
\hline$B_{\mathrm{E}}\left(\mathrm{mg} \mathrm{g}^{-1} \min ^{-1}\right)$ & 0.32 & 0.49 \\
\hline$R^{2}$ & 0.8133 & 0.7835 \\
\hline
\end{tabular}

The pseudo-second-order kinetic model given in Eq. 5 considers the rate-limiting step as the formation of a chemisorptive bond involving sharing or exchange of electrons between the sorbate and the sorbent.

$t / q_{t}=1 / k_{2} q_{\mathrm{e}}^{2}+1 / q_{\mathrm{e}} t$,

where $k_{2}$ is the pseudo-second-order rate constant $\left(\mathrm{g} \mathrm{mg}^{-1} \mathrm{~min}\right)$. The initial sorption rate, $h\left(\mathrm{mg} \mathrm{g}^{-1} \mathrm{~min}\right)$ can be defined as

$h=k_{2} q_{\mathrm{e}}^{2}$.

The initial sorption rate, $h$ predicts the behavior over the whole range of time and is in agreement with chemisorption being the rate controlling step. The pseudosecond-order parameters, $q_{\mathrm{e}, \text { cal }}, k_{2}$ and $h$ were calculated from the linear plot of $t / q t$ versus $t$ (Fig. $4 \mathrm{~b}$ ). In the case of pseudo-second-order model, the calculated $q_{\mathrm{e}}$ values agreed well with the experimental $q_{\mathrm{e}}$ values, also the rate constant of pseudo-second-order adsorption $\left(k_{2}\right)$ obtained from thiourea-functionalized silica was found to be lower than that computed for derived silica (Table 1), this indicates that the uptake of $\mathrm{Cd}$ ions onto thiol-functionalized silica from aqueous solution was more rapid and favorable. In addition to this, initial sorption rate $(h)$, calculated using Eq. 6 gave higher value for thiourea-functionalized silica $\left(0.118 \mathrm{mg} \mathrm{g}^{-1} \mathrm{~min}^{-1}\right)$ than derived silica $\left(0.095 \mathrm{mg} \mathrm{g}^{-1} \mathrm{~min}^{-1}\right)$. This is an indication that initial adsorption of $\mathrm{Cd}$ ions by thiourea-functionalized silica was faster. Furthermore, the correlation coefficient $R^{2}$ for pseudo-second-order model was much closer to unity than the correlation coefficient for pseudo-first order model as shown in Table 1. These suggest that the pseudo-secondorder adsorption mechanism is more operative in the $\mathrm{Cd}$ ion adsorption process.

Elovich model as shown in Eq. 7 has been useful in describing adsorption on highly heterogeneous adsorbents.

$q_{t}=\left(1 / A_{\mathrm{E}}\right) \ln \left(B_{\mathrm{E}} A_{\mathrm{E}}\right)+\left(1 / A_{\mathrm{E}}\right) \ln (t)$,

where $B_{\mathrm{E}}$ is the initial adsorption rate $\left(\mathrm{mg} \mathrm{g}^{-1} \mathrm{~min}\right)$ and $A_{\mathrm{E}}$ is related to the extent of surface coverage, desorption constant and the activation energy for chemisorption $\left(\mathrm{g} \mathrm{mg}^{-1}\right)$. A plot of $q_{t}$ vs. $\ln (t)$ gives a straight line with a slope of $A_{\mathrm{E}}$ and an intercept of $B_{\mathrm{E}}$. In Table 1, the higher value of $A_{\mathrm{E}}$ for derived silica indicates more available surface for $\mathrm{Cd}$ ions on derived silica and less available surface on thiolfunctionalized silica. On the other hand, the higher value of $B_{\mathrm{E}}$ for thiol-functionalized silica shows a greater affinity in adsorption increased while desorption decreased. 


\section{Adsorption isotherms}

An appropriate adsorption model can help in understanding process mechanism, analyze experimental data, predict answer to operational conditions, and optimize processes. The Langmuir (1916), Freundlich (1906), Temkin and Pyzhev (1940), Dubinin and Radushkevich (1947), Harkins and Jura (1944) and Halsey (Halsey 1948) isotherm models were, respectively, used to analyze the equilibrium experimental data for sorption of $\mathrm{Cd}$ ions onto derived and thiol-functionalized silica by varying initial metal ion concentrations from 25 to $500 \mathrm{mg} \mathrm{L}^{-1}$ at $28,35,45,55$ and $65{ }^{\circ} \mathrm{C}$. To evaluate the fit of isotherm equations to the experimental data, different error functions of nonlinear regression basis were used to measure the isotherm constants and compare them with the less accurate linearized analysis values. The residual root mean square error (RMSE) and the Chi-square test were used. RMSE can be defined as (Vijayaraghavan et al. 2006)

$\mathrm{RMSE}=\sqrt{\frac{1}{n} \sum_{i=1}^{n}\left(q_{\mathrm{e}, \mathrm{exp}}-q_{\mathrm{e}, \mathrm{calc}}\right)^{2} .}$

The subscripts "exp" and "calc" show the experimental and calculated values and $\mathrm{n}$ is the number of observations in the experimental isotherm. The smaller the RMSE value, the better the curve fitting. The Chi-square test (Ho et al. 2005) is given as

$\chi^{2}=\sum_{i=1}^{n} \frac{\left(q_{\mathrm{e}, \exp }-q_{\mathrm{e}, \mathrm{calc}}\right)^{2}}{q_{\mathrm{e}, \mathrm{exp}}}$.

The lower the value of $\chi^{2}$, the higher the accuracy, validity and fitness of the model.

The model equations are shown below (Eqs. 10-15):

$C_{\mathrm{e}} / q_{\mathrm{e}}=1 / K_{\mathrm{L}} q_{\max }+C_{\mathrm{e}} / q_{\max } \quad$ (Langmuir),

$\log q_{\mathrm{e}}=\log K_{\mathrm{F}}+1 / n \log C_{\mathrm{e}} \quad$ (Freundlich),

$q_{\mathrm{e}}=\left(R T / b_{\mathrm{T}}\right) \ln A_{\mathrm{T}}+\left(R T / b_{\mathrm{T}}\right) \ln C_{\mathrm{e}} \quad($ Temkin $)$,

$\ln \left(q_{\mathrm{e}}\right)=\ln \left(q_{\mathrm{s}}\right)-k_{\mathrm{ad}} \varepsilon^{2} \quad$ (Duibnin - Radushkevich),

$1 / q_{\mathrm{e}}^{2}=(B / A)-(1 / A) \log C_{\mathrm{e}} \quad$ (Harkins-Jura),

$\log q_{\mathrm{e}}=\left(1 / n_{\mathrm{H}}\right) \log K_{\mathrm{H}}-\left(1 / n_{\mathrm{H}}\right) \log C_{\mathrm{e}} \quad$ (Halsey),

where $q_{\mathrm{e}}$ is the adsorption capacity in equilibrium $\left(\mathrm{mg} \mathrm{g}^{-1}\right)$, $C_{\mathrm{e}}$ is the sorbate equilibrium concentration $\left(\mathrm{mg} \mathrm{L}^{-1}\right), K_{\mathrm{L}}$ $\left(\mathrm{L} \mathrm{mg}^{-1}\right)$ is the Langmuir constant associated to energy of adsorption and $q_{\max }$ denotes the theoretical monolayer adsorption capacity $\left(\mathrm{mg} \mathrm{g}^{-1}\right) . K_{\mathrm{F}}$ is the Freundlich constant $\left(\mathrm{mg} \mathrm{g}^{-1}\right)\left(\mathrm{L} \mathrm{mg}^{-1}\right)^{1 / n}$ while $1 / n$ represents dimensionless heterogeneity factor. $b_{\mathrm{T}}$ is the Temkin constant related to heat of adsorption $\left(\mathrm{J} \mathrm{mol}^{-1}\right) . A_{\mathrm{T}}$ is the equilibrium binding constant $\left(\mathrm{L} \mathrm{g}^{-1}\right)$ corresponding to the maximum binding energy. $q_{\mathrm{s}}$ is the $\mathrm{D}-\mathrm{R}$ isotherm constant $\left(\mathrm{mg} \mathrm{g}^{-1}\right), \varepsilon$ represents the Polanyi potential constant $\left(\mathrm{kJ}^{2} \mathrm{kmol}^{-2}\right)$ is given as $R T \ln \left(1+1 / C_{\mathrm{e}}\right), R$ is the universal gas constant, $T$ is the temperature (K) and $k_{\text {ad }}\left(\mathrm{mol}^{2} \mathrm{~kJ}^{-2}\right)$ indicates the activation energy, $E\left(\mathrm{~kJ} \mathrm{~mol}^{-1}\right)$ of adsorption per molecule of sorbate when it is transferred to the surface of the solid from infinity in the solution, where $E=1 / \sqrt{ }-2 k_{\mathrm{ad}} . A$ and $B$ are Harkins-Jura isotherm parameter and constant, $K_{\mathrm{H}}$ and $n$ are the Halsey isotherm constant and exponent.

The Langmuir isotherm model assumes that the activity of every site on the surface of sorbent is identical and equivalent, and the sorbate is adsorbed homogeneously without interaction. The increasing values of $q_{\max }$ for derived and thiol-functionalized silica with respect to an increase in temperature (Table 2), demonstrated an endothermic process.

The value of $k_{\mathrm{L}}(\mathrm{L} / \mathrm{mg})$ parameter of the Langmuir model is the constant representing the affinity of sorbate to sorbent. Higher $k_{\mathrm{L}}$ values mean more affinity of sorbate to sorbent. $k_{\mathrm{L}}$ parameter of the Langmuir model (Table 2) for the sorption of $\mathrm{Cd}$ onto derived and thiourea-functionalized silica in this study increases with increase in temperature for both sorbents, indicating that higher the temperature, higher will be the swelling of the internal structure of the adsorbent materials to increase the monolayer adsorption capacity value $\left(q_{\max }\right)$ and accommodate more $\mathrm{Cd}$ molecules on its surface.

To determine whether the adsorption is favorable, a dimensionless constant, commonly known as separation factor $\left(R_{\mathrm{L}}\right)$ is calculated. The obtained $R_{\mathrm{L}}$ value for the sorption of Cd onto derived and thiol-functionalized silica is less than 1 and greater than zero, as shown in Table 2, indicating favorable adsorption. A plot of $C_{\mathrm{e}} / q_{\mathrm{e}}$ against $C_{\mathrm{e}}$ for the adsorption of $\mathrm{Cd}$ ion onto derived and thiol-functionalized silica was shown in Fig. 5a, b, respectively. The Langmuir isotherm was found to be linear over the entire concentration range with good linear correlation coefficients and also the Chi-square, $\chi^{2}$ and RMSE values gave a good fits to the experimental data for both adsorbents. The maximum sorption capacity calculated from Langmuir isotherm was 27.55 and $28.41 \mathrm{mg} \mathrm{g}^{-1}$ for derived and thiourea-functionalized silica.

These values obtained from maize husk and stem derived and thiourea-functionalized silica are comparable to the adsorption capacities found for different types of hybrid silica materials: aminopropylMCM-41: $30.5 \mathrm{mg} \mathrm{g}^{-1}$ (Algarra et al. 2005); mercapto propyl-functionalized porous silica: $13 \mathrm{mg} \mathrm{g}^{-1}$ (Lee et al. 2001); EDTA modified SBA-15: $13.2 \mathrm{mg} \mathrm{g}^{-1}$ (Jiang et al. 2007); chitosan immobilized on silica surface: $0.06 \mathrm{mmol} \mathrm{g}^{-1}$ (Budnyak et al. 2014); micron-sized polymer with silica: $13.74 \mathrm{mg} \mathrm{g}^{-1}$ (Kanna et al. 2015); 


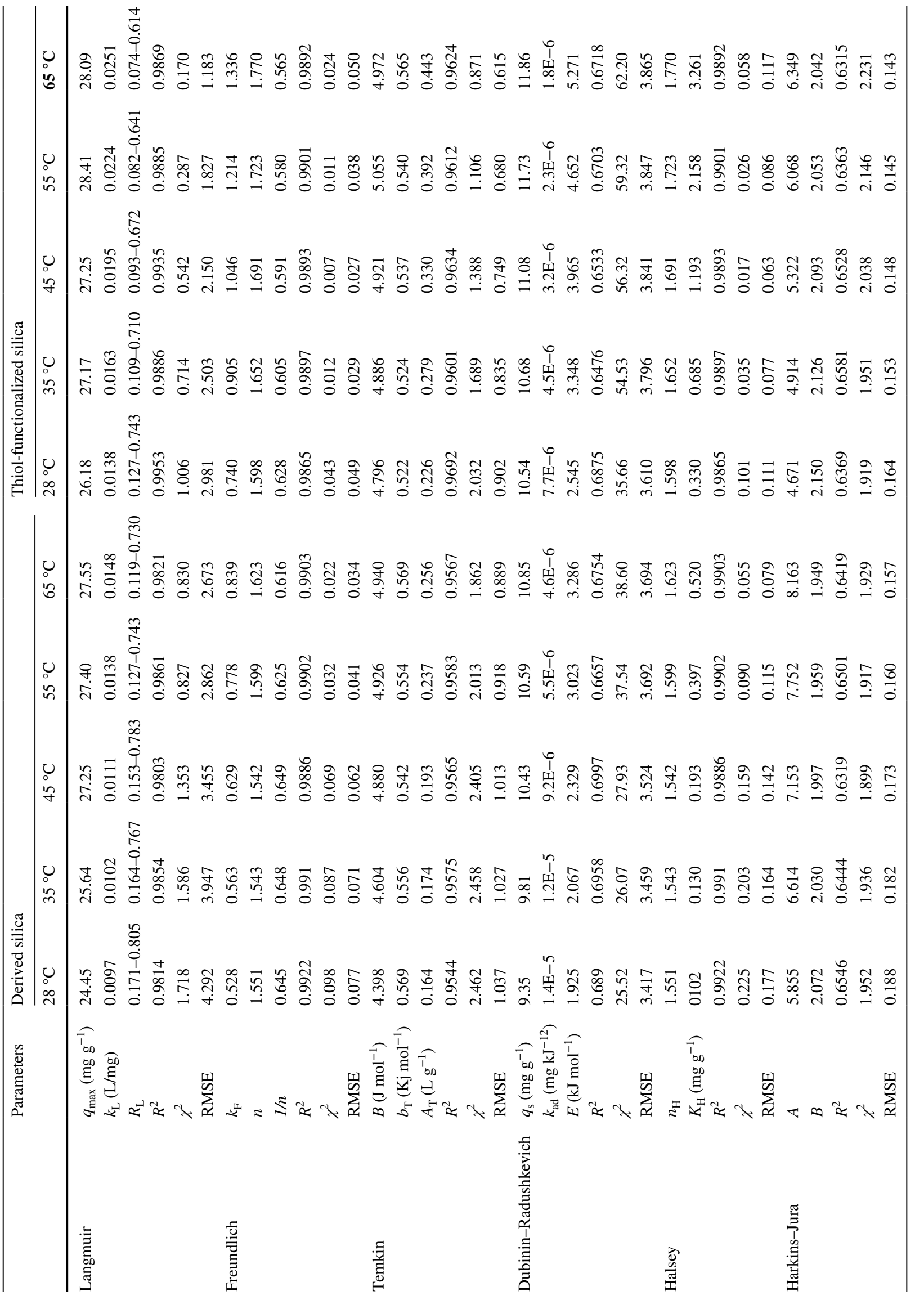




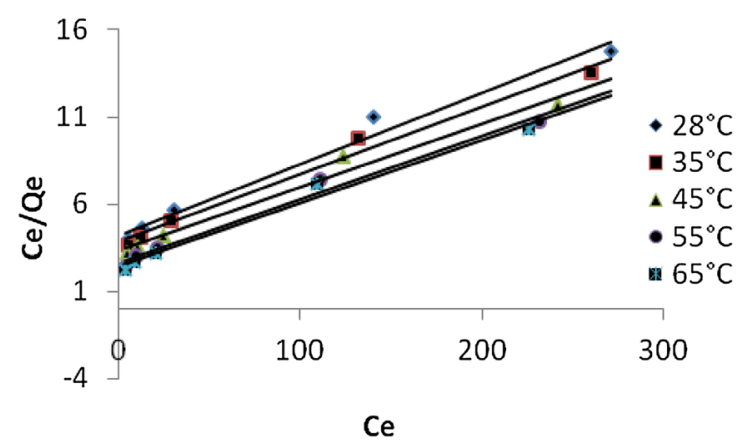

(a)

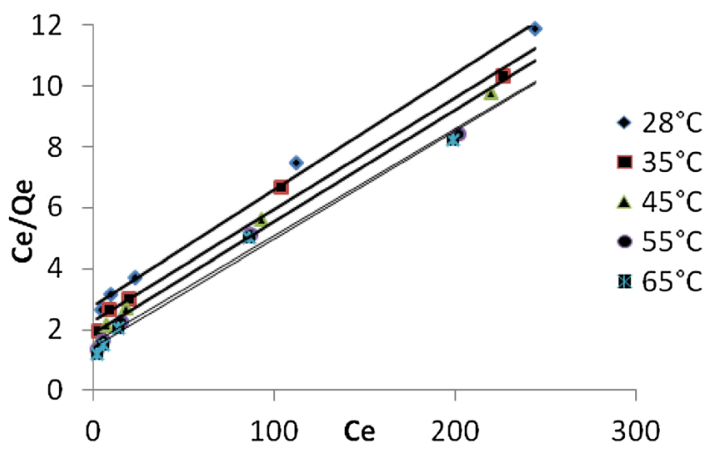

(b)

Fig. 5 Langmuir isotherm plot for $\mathbf{a}$ derived and $\mathbf{b}$ thiol-functionalized silica

Poly(ethyleneimine)-functionalized silica: $31.8 \mathrm{mg} \mathrm{g}^{-1}$ (Hongbo et al. 2015); amine-functionalized MCM-48: $33 \mathrm{mg} \mathrm{g}^{-1}$ (Taba et al. 2017); silica materials prepared by microwave synthesis: $32.3 \mathrm{mg} \mathrm{g}^{-1}$ (Zhu et al. 2017); carbamoyl phosphoric acid on mesoporous silica: $35.5 \mathrm{mg} \mathrm{g}^{-1}$ (Yantasee et al. 2003); thiol-functionalized silica on poly(ether sulfone) membrane: $39 \mathrm{mg} \mathrm{g}^{-1}$ (Rezvani-Boroujeni et al. 2017). Hence, silica derived from low cost agricultural waste materials can be easily functionalized using various organic species and will be interesting candidates for application in heavy metal removal from wastewater.

The Freundlich isotherm model is based on multilayer adsorption. The Freundlich exponent, $n$, should have a value lying in the range of $1-10$ for classification as favorable adsorption; both the adsorbents indicated that the adsorption of $\mathrm{Cd}$ was favorable as shown in Table 2. Figure $6 \mathrm{a}, \mathrm{b}$ showed that, the Freundlich isotherm presented a better fit to the experimental data as indicated by $R^{2}, \chi^{2}$ and RMSE (Table 2), resulting in a better fit to adsorption data than the other isotherm models used.

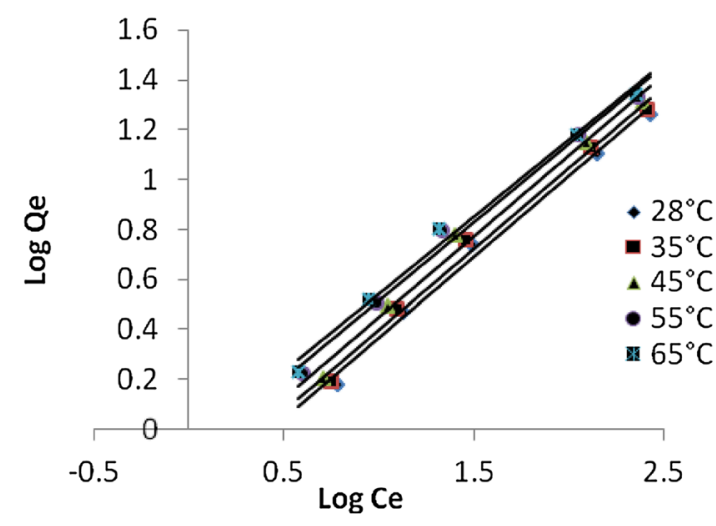

(a)
The numerical value of $1 / n<1$ indicates that adsorption capacity is only slightly suppressed at lower equilibrium concentrations. This isotherm does not predict any saturation of the sorbate, thus, infinite surface coverage is mathematically predicted, indicating multilayer adsorption on the surface (Neto et al. 2011). In addition, the $n$ values were higher than 1, which prove a proper course of adsorption process and its physical nature (Ciesielczyk et al. 2016). The Freundlich constant $k_{\mathrm{F}}$, which is related to adsorption capacity, increased with temperature (Table 2), indicating that the adsorption process is endothermic. $k_{\mathrm{F}}$ values which are higher for thiol-functionalized silica confirmed that the adsorption capacity of thiol-functionalized silica was greater than that of the derived silica. The $R^{2}, \chi^{2}$ and RMSE values showed better fitness of Freundlich model as compared to the other isotherm models used, indicating the multilayer formation on heterogeneous surface of the adsorbents.

Temkin isotherm contains a factor that explicitly takes into account of adsorbent-adsorbate interactions. By ignoring the extremely ion and large values of concentrations, the model assumes that heat of adsorption (function of

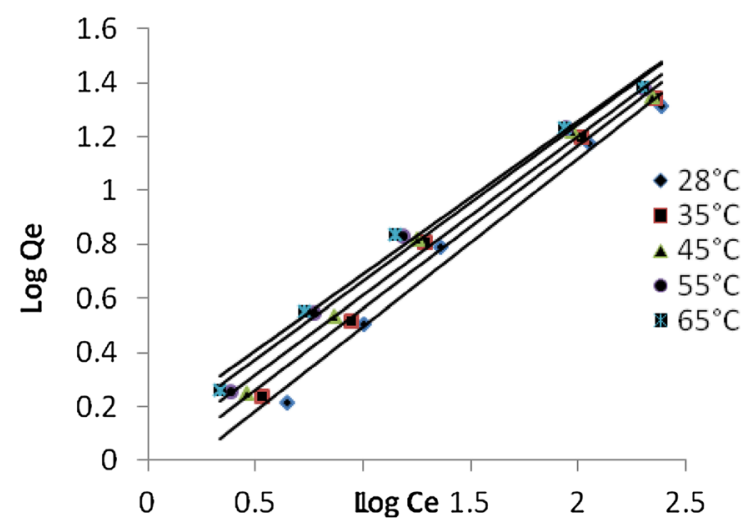

(b)

Fig. 6 Freundlich isotherm plot for $\mathbf{a}$ derived and $\mathbf{b}$ thiol-functionalized silica 
temperature) of all molecules in the layer would decrease linearly rather than logarithmic with coverage (Temkin and Pyzhev 1940). The increase in maximum binding energy $\left(A_{\mathrm{T}}\right)$ for derived and thiol-functionalized silica with respect to increase with temperature implies that the interaction of $\mathrm{Cd}$ molecules with the adsorption sites was more at higher temperature and the system was influenced by thermal properties. The Temkin isotherm, $B$, of both derived and thiol-functionalized silica (Table 2) shows that the heat of adsorption increases with increase in temperature, indicating endothermic adsorption. Also, the $b_{\mathrm{T}}$ values for both derived thiourea-functionalized silica across the various temperatures were less than $8 \mathrm{~kJ} \mathrm{~mol}^{-1}$, suggesting weak interaction between $\mathrm{Cd}$ ions and the adsorbents used, indicating that process would be physisorption (Theivarasu and Mylsamy 2010). The obtained correlation coefficient for derived and thiol-functionalized silica were high and with low values for Chi-square $\chi^{2}$, and RMSE confirms the better fit of Temkin model to the experimental data.

The Dubinin-Radushkevich model describes the adsorption nature of the sorbate on the adsorbent and is used to calculate the mean free energy of adsorption. The slope and intercept of plots of $\ln q_{\mathrm{e}}$ versus $\varepsilon^{2}$ at different temperature were used to calculate the D-R isotherm parameters as shown in Table 2. The value of $q_{\mathrm{s}}$ for derived and thiourea-functionalized silica was $\left(9.35-10.85 \mathrm{mg} \mathrm{g}^{-1}\right)$ and (10.54-11.86 $\mathrm{mg} \mathrm{g}^{-1}$ ), respectively, which is not consistent with the experimental capacity in comparison with the corresponding Langmuir parameter $\left(q_{\max }\right)$ which is almost two times of the experimental capacity as shown in Table 2 . This might be attributed to different assumptions taken into consideration while formulating the isotherms.

The mean adsorption energy, $E$, gives information about chemical and physical sorptions. The $E$ values ranges for $1-8 \mathrm{~kJ} \mathrm{~mol}^{-1}$ for physical sorption and from 8 to $16 \mathrm{~kJ} \mathrm{~mol}^{-1}$ for chemical sorption (Sari et al. 2007). The calculated $E$ values from $\mathrm{D}$ to $\mathrm{R}$ isotherm for both derived and thiolfunctional ranges between 1.925 and $5.271 \mathrm{~kJ} \mathrm{~mol}^{-1}$ (less than $8 \mathrm{~kJ} \mathrm{~mol}^{-1}$ ), indicating that the type of sorption of $\mathrm{Cd}(\mathrm{II})$ is physical sorption and this was also confirmed by the Temkin model. The high value of Chi-square $\chi^{2}$ and the magnitude of the correlation coefficients of D-R isotherm is the lowest when compared to the other isotherm models used. This suggests that the $\mathrm{Cd}$ adsorption onto derived and thiol-functionalized silica does not show a satisfactory fit to the experimental data for the Dubinin-Radushkevich isotherm model.

The Harkins-Jura adsorption isotherm accounts for multilayer adsorption and can be explained with the existence of a heterogeneous pore distribution (Harkins and Jura 1944). This method can be employed when different types of pores are involved in an adsorbent. Harkins-Jura isotherm constants $A$ and $B$ were calculated from a linear plot of $1 / q_{\mathrm{e}}^{2}$ versus $\log C_{\mathrm{e}}$ and data obtained are presented in Table 2 . The constant $A$ for the adsorption of $\mathrm{Cd}$ onto derived and thiolfunctionalized silica increases with increase in temperature and the constant $B$ decreases with increase in temperature. These account for the heterogeneous nature of both adsorbents. When the adsorption proceeds, the accumulation of cadmium ion on the adsorbent surface at higher temperature was not favored. The correlation coefficient obtained for both adsorbents were not high, this reveals that Harkin-Jura model could not describe the experimental isotherm data in the sorption of $\mathrm{Cd}$ ion onto derived and thiol-functionalized silica.

The Halsey isotherm model is used for heteroporous solids. This model is suitable for multilayer metal adsorption. The correlation coefficient fitting of the Halsey isotherm equation was high for derived and thiol-functionalized silica and its corresponding Chi-square $\chi^{2}$ and RMSE values in Table 2 concurred with this result, which is an indication of the heteroporosity of $\mathrm{Cd}$ ion and also implies the presence of physical forces in the adsorption process at the lower temperature.

The obtained data from the two adsorption systems followed the six investigated isotherm models in the following order: Freundlich $>$ Halsey $>$ Langmuir $>$ Temkin $>$ Harkin-Jura $>$ Dubinin-Radushkevich. The correlation coefficients for Freundlich and Halsey isotherms were highest in comparison to the values obtained from other isotherms and were a pointer to the heterogeneity of the surface of adsorbents and the multilayer adsorption nature of the cadmium ions onto the adsorbents.

\section{Effect of temperature and thermodynamic studies}

Effect of temperature on the adsorption of derived and thiol-functionalized silica was studied at different concentrations; $25-500 \mathrm{mg} \mathrm{L}^{-1}$ at $28-65{ }^{\circ} \mathrm{C}$. It was observed that an increase in temperature led to increases in the percentage removal of cadmium(II) by both adsorbents, indicating endothermic nature of adsorption system. This might be ascribed to the increase in the rate of diffusion of adsorbate molecules across the external boundary layer and internal pores of the adsorbent. Thermodynamic considerations of adsorption process are necessary to conclude whether the process is spontaneous. The change in Gibbs free energy, $\Delta G^{0}$, is an indication of spontaneity of a chemical reaction and therefore is an important criterion for spontaneity. Also, enthalpy, $\Delta H^{0}$ and entropy, $\Delta S^{0}$ factors must be considered to determine the Gibbs free energy of the process. The thermodynamic parameters of Gibb's free energy change, $\Delta G^{0}$, enthalpy change, $\Delta H^{0}$, and entropy change, $\Delta S^{0}$, for the adsorption processes are calculated using the following equations:

$\Delta G^{0}=-R T \ln K$, 
$\Delta G^{0}=\Delta H^{0}-T \Delta S^{0}$,

where $R$ is the universal gas constant and $T$ is the absolute temperature (K). $\Delta H\left(\mathrm{~kJ} \mathrm{~mol}^{-1}\right)$ and $\Delta S\left(\mathrm{~J} \mathrm{~mol}^{-1} \mathrm{~K}^{-1}\right)$ of sorption can be calculated from the slope and intercept of the plot of $\ln K$ and 1/T (Van't Hoff plot). The Van't Hoff plot gave a straight line.

As shown in Table 3, the positive values of $\Delta H^{0}$ suggest the endothermic nature of adsorption. One possible interpretation of endothermicity of adsorption was that the metal ions were highly solvated in water, in order for these ions to be adsorbed, the hydration sphere must be removed and the process requires energy intake. The energy of dehydration supersedes that required for getting the ions attached to the surface of the adsorbent. The low positive $\Delta H^{0}$ values depict that $\mathrm{Cd}$ ion is physically adsorbed onto derived and thiolfunctionalized silica, and it was further bolstered because the mean $\Delta H^{0}$ value obtained in this study was lower than $40 \mathrm{~kJ} \mathrm{~mol}^{-1}$ (Bhatnagar et al. 2009, Ponnusami et al. 2009).

The positive value of $\Delta S^{0}$ shows increased randomness at the adsorbent-solution interface during the adsorption of metal ions on derived and thiol-functionalized silica. The adsorbed water molecules, which are displaced by adsorbate species, gain more translational entropy than is lost by the adsorbate molecules, thus allowing the prevalence of randomness in the system (Gopal and Elango 2007).

The negative values of $\Delta G^{0}$ decreased with an increase in temperature, suggesting that a better adsorption is actually obtained at higher temperature. This is because at higher temperature, ions are easily desolvated and therefore their adsorption become more favorable. The negative values of $\Delta G^{0}$ indicate the spontaneous nature and feasibility of the adsorption process at the range of temperature studied.

\section{Desorption study}

Desorption studies help elucidate the nature of adsorption and recycling of the spent adsorbent and the metal ions. The effects of various reagents used for desorption studies are shown in Fig. 7. Among the solvents, distilled water, $\mathrm{CH}_{3} \mathrm{COOH}$ and $\mathrm{NaOH}$ had a limited amount of $\mathrm{Cd}$ ion recovery $(<40 \%)$ for both adsorbents. The highest $(84 \%)$ recovery was found with the use of $0.1 \mathrm{~N} \mathrm{HCl}$ for derived silica and $(88 \%)$ recovery was found with the use of $0.1 \mathrm{~N}$ $\mathrm{HNO}_{3}$ for thiourea-functionalized silica. The adsorption-desorption cycle of the metal ion was repeated five times using the various reagents with the same adsorbents. The adsorption capacities for the both adsorbents did not noticeably change during the repeated adsorption desorption operations, especially for the non-acidic solvent but 3-5\% change was observed for the acidic reagent after the fifth cycle. This can be attributed to the decomposition effect of the acid solution. These results show that the absorbents

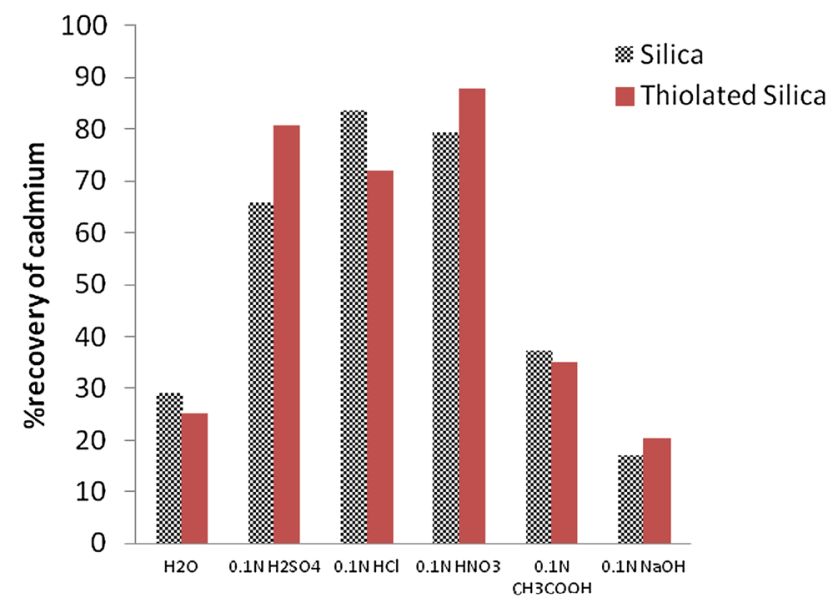

Fig. 7 Desorption of $\mathrm{Cd}$ ions from derived and thiol-functionalized silica

Table 3 Thermodynamic parameters for adsorption of cadmium ions

\begin{tabular}{|c|c|c|c|c|c|c|c|c|}
\hline & \multirow[t]{2}{*}{$C_{\mathrm{o}}\left(\mathrm{mg} \mathrm{L}^{-1}\right)$} & \multicolumn{5}{|c|}{$\Delta G^{0}\left(\mathrm{~kJ} \mathrm{~mol}^{-1}\right)$} & \multirow[t]{2}{*}{$\Delta H^{0}\left(\mathrm{~kJ} \mathrm{~mol}^{-1}\right)$} & \multirow[t]{2}{*}{$\Delta S^{0}\left(\mathrm{~J} \mathrm{~mol}^{-1} / \mathrm{K}\right)$} \\
\hline & & $301^{\circ} \mathrm{K}$ & $308^{\circ} \mathrm{K}$ & $318^{\circ} \mathrm{K}$ & $328^{\circ} \mathrm{K}$ & $338^{\circ} \mathrm{K}$ & & \\
\hline \multirow[t]{5}{*}{ Derived silica } & 25 & -2.870 & -3.142 & -3.602 & -4.513 & -4.864 & 14.401 & 57.121 \\
\hline & 50 & -2.506 & -2.839 & -3.317 & -3.884 & -4.320 & 12.474 & 49.740 \\
\hline & 100 & -1.996 & -2.314 & -2.905 & -3.501 & -3.785 & 13.316 & 50.815 \\
\hline & 300 & -0.327 & -0.625 & -0.951 & -1.441 & -1.554 & 10.143 & 34.911 \\
\hline & 500 & 0.411 & 0.202 & -0.170 & -0.410 & -0.555 & 8.559 & 27.193 \\
\hline \multirow{5}{*}{$\begin{array}{l}\text { Thiol-functional- } \\
\text { ized silica }\end{array}$} & 25 & -3.870 & -4.763 & -5.409 & -6.086 & -6.617 & 17.743 & 72.479 \\
\hline & 50 & -3.458 & -3.965 & -4.653 & -5.488 & -5.975 & 17.553 & 69.869 \\
\hline & 100 & -3041 & -3.636 & -4.029 & -4.657 & -5.105 & 13.327 & 54.678 \\
\hline & 300 & -1.286 & -1.618 & -2.113 & -2.432 & -2.564 & 9.482 & 36.047 \\
\hline & 500 & -0.122 & -0.488 & -0.647 & -1.068 & -1.169 & 8.366 & 28.451 \\
\hline
\end{tabular}


have good regeneration ability. Desorption of metal ion by mineral acids and alkaline medium indicates that the metal ion was adsorbed onto derived silica and thiol-functionalized silica through physisorption as well as by chemisorption mechanism (Anirudhan and Sreedhar 1999).

\section{Conclusion}

In this study, the ability of derived and thiol-functionalized silica to adsorbed cadmium from aqueous solution has been explored. The thiourea-functionalization of the adsorbent has been shown to enhance the adsorption capacity. The thiourea-functionalized silica showed higher adsorption selectivity for cadmium ion compared to derived silica. This shows the effect of the thiol-functionalization on the surface of the silica. The chemical stability of the adsorbent materials both in acidic and basic media allows the reuse of the adsorbents for several cycles. The kinetic studies revealed that the adsorption process best fit the pseudo-second-order kinetic model for both the adsorbents. Equilibrium adsorption data fitted best in Freundlich isotherm, Halsey isotherm, Langmuir isotherm and Temkin isotherm with high $R^{2}$, low RMSE and low $\chi^{2}$ values confirming good agreement between the theoretical models and our experimental results. The correlation coefficients for Freundlich and Halsey isotherms were highest in comparison to the values obtained from other isotherms and were a pointer to the heterogeneity of the surface of the adsorbents and the multilayer adsorption nature of the cadmium ions onto the adsorbents. The sorption of $\mathrm{Cd}(\mathrm{II})$ on both adsorbents indicates the physical nature of the adsorption process in this study. This was confirmed by Freundlich, Temkin and Dubinin-Radushkevich isotherm models. Additionally, it was further supported by the $\Delta H^{0}$ values as obtained in this study. Thermodynamic studies revealed that the adsorption process was endothermic, feasible and spontaneous in nature, with good affinity toward the sorbent. This study has shown that the derived and thiourea-functionalized silica from agricultural wastes are promising adsorbents for the removal of $\mathrm{Cd}$ ions from aqueous solution.

Open Access This article is distributed under the terms of the Creative Commons Attribution 4.0 International License (http://creativecomm ons.org/licenses/by/4.0/), which permits unrestricted use, distribution, and reproduction in any medium, provided you give appropriate credit to the original author(s) and the source, provide a link to the Creative Commons license, and indicate if changes were made.

\section{References}

Algarra M, Jimenez MV, Rodriguez-Castellon E, Jimenez-Lopez A, Jimenez-Jimenez J (2005) Heavy metals removal from electroplating wastewater by aminopropyl-Si MCM-41. Chemosphere 59:779-786

Allen LH, Matijevic E (1970) Stability of colloidal silica II. Ionexchange. J Colloid Interface Sci 33(3):421-429

Al-Owein R, El-Rassy H (2009) Synthesis and characterization by FTIR spectroscopy of silica xerogels prepared using several $\mathrm{Si}(\mathrm{OR})_{4}$ and $\mathrm{R}^{\prime \prime} \mathrm{Si}\left(\mathrm{OR}^{\prime}\right)_{3}$ precursors. J Mol Struct 919:140-145

Anirudhan TS, Sreedhar MK (1999) Mercury(II) adsorption of desorption characteristics of coconut husk based carbon-kinetics and self diffusion. Ind J Environ Proj 19:8

Arakaki LNH, Nunes LM, Simoni JA, Airoldi C (2000) Ethyleneimine anchored on thiol-modified silica gel surface adsorption of divalent cations and calorimetric data. J Colloid Interface Sci 228:46-51

Balistrieri LS, Murray JW (1981) The surface Chemistry of goethite (alpha-FeOOH) in major ion sea water. Am J Sci 281:788-806

Bhatnagar A, Kumar E, Minocha AK, Jeon BH, Song H, Seo YC (2009) Removal of anionic dyes from water using Citrus limonum (lemon) peel: equilibrium studies and kinetic modeling. Sep Sci Technol 44:316-334

Budnyak T, Tertyka V, Yanavska E (2014) Chitosan immobilized on silica surface for wastewater treatment. Mater Sci (Medziagotyra) 20(2):177-182

Ciesielczyk F, Bartczak P, Jesionowski T (2016) Removal of cadmium(II) and lead(II) ions from model aqueous solutions using sol-gel-derived inorganic oxide adsorbent. Adsorption 22:445-458

Dubinin MM, Radushkevich LV (1947) Equation of the characteristic curve of activated charcoal. Proc Acad Sci USSR Chem Sect 55:331-333

Freundlich HMF (1906) Über die adsorption in Lòsungen. Zeitschrift für Physikalische Chemie (Leipzig) 57A:385-470

Gopal V, Elango P (2007) Kinetic and thermodynamic investigations of adsorption of fluoride onto activated aloe vera carbon. J Indian Chem Soc 84:1114-1118

Halsey G (1948) Physical adsorption on non-uniform surface. J Chem Phys 16:931-937

Harkins WD, Jura GJ (1944) The decrease of free surface energy as a basis for the development of equations for adsorption isotherms and the existence of two condensed phases in films on solid. J Chem Phys 12:112-113

Ho YS, Chiu WT, Wang CC (2005) Regression analysis for the adsorption isotherm of basic dye on sugarcane dust. Bioresour Technol 96:1285-1291

Hongbo X, Dan-dan L, Lu H (2015) Adsorption of Cu(II) from a wastewater effluent of electroplating industry by poly(ethyleneimine)functionalized silica. Iran J Chem Eng 34(2):73-81

Hua M, Zhang S, Pan B, Zhangc W, Lv L, Zhang Q (2012) Heavy metal removal from water/wastewater by nanosized metal oxides: a review. J Hazard Mater 211:317-331

Jiang Y, Gao Q, Yu H, Chen Y, Deng F (2007) Intensively competitive adsorption for heavy metal ions by PAMAM-SBA-15 and EDTAPAMAM-SBA-15 inorganic-organic hybrid materials. Micropor Mesopor Mater 103:316-324

Kamath SR, Proctor A (1998) Silica gel from rice husk ash: preparation and characterization. Cereal Chem 75:484-487

Kanna RS, Kavitha K, Muthukrishnan P, Krishnan NP, Illayaraja M (2015) Convienent synthesis of micron-sized macro porous polymer with silica on their surfaces and excellent adsorption performance of $\mathrm{Pb}(\mathrm{II})$ ion. J Environ Anal Toxicol 5(4):291 
Khosravan M (2009) Synthesis, characterization of silica gel phases chemically immobilized with -2-aminothiophenol and the use of it for preconcentration and determination of trace amounts of copper and batch studies by flame atomic absorption spectrometry. Eur J Sci Res 34:228-236

Langmuir I (1916) The constitution and fundamental properties of solids and liquids. J Am Chem Soc 38:2221-2295

Lee H, Yi J (2001) Removal of copper ions using functionalized mesoporous silica in aqueous solution. Sep Sci Technol 36:2433-2448

Lee B, Kim Y, Lee H, Yi J (2001) Synthesis of functionalized porous silicas via templating method as heavy metal ion adsorbents: the introduction of surface hydrophilicity onto the surface of adsorbents. Microporous Mesoporous Mater 50:77-90

Liu AM, Hidajat S, Zhao DY (2000) A new class of hybrid mesoporous materials with functionalized organic monolayers for selective adsorption of heavy metal ions. Chem Commun 13:1145-1146

Neto VO, Oliveira AG, Teixeira NP, Silva AA, Freire TC, Keukeleire DD, Nascimento RF (2011) Use of coconut bagasse as alternative adsorbent for separation of $\mathrm{cu}(\mathrm{II})$ ions from aqueous solutions: isotherms, kinetics, and thermodynamic studies. Bioresource 6(3):3376-3395

Perez-Quintanilla D, del Hierro I, Fajardo M, Sierra I (2006) 2-mercaptothiazoline modified mesoporous silica for mercury removal from aqueous media. J Hazard Mater 134:245-256

Piao Y, Burns A, Kim J, Wiesner U, Hyeon T (2008) Designed fabrication of silica-based nanostructured particle systems for nanomedicine applications. Adv Funct Mater 18(23):3745-3758

Ponnusami V, Aravindhan R, Karthik raj N, Ramadoss G, Srivastava SN (2009) Adsorption of methylene blue onto gulmohar plant leaf powder: equilibrium, kinetic, and thermodynamic analysis. J Environ Prot Sci 3:1-10

Rezvani-Boroujeni A, Javanbakht M, Karimi M, Akbari-Adergani B (2017) Adsorption properties of thiol-functionalized silica nanoparticles prepared for application in poly(ether sulfone) nanocomposite membranes. J Text Polym 5(1):37-47

Salim R, Al-Subu M, Dawod E (2008) Efficiency of removal of cadmium from aqueous solution by plant leaves and the effects of interaction of combinations of leaves on their removal efficiency. J Environ Manag 87:521-532

Sari A, Tuzen M, Citak D, Soylak M (2007) Adsorption characteristic of $\mathrm{Cu}$ (II) and $\mathrm{Pb}$ (II) onto expanded perlite from aqueous solution. J Hazard Mater 148:387-394

Satya N, Ojha CSP, Mishra K, Chaube UC, Sharma PK (2011) Cadmium and chromium removal by aquatic plant. Int J Environ Sci $1: 8$

Sharma YC (2008) Thermodynamics of removal of cadmium by adsorption on an indigenous clay. Chem Eng J 145:64-68

Socrates G (1994) Infrared and Raman characteristic group frequencies. Table and charts, 2nd edn. Wiley, New York

Stanton J, Maatman RW (1963) The reaction between aqueous uranyl ion and the surface of silica gel. J Colloid Sci 18(2):132-146
Taba P, Budi P, Puspitasari AY (2017) Adsorption of heavy metals on amine-functionalized MCM-48. IOP Conf Ser Mater Sci Eng 188:012015

Tangjuank S, Insuk N, Tontrakoon J, Udeye V (2009) Adsorption of lead(II) and cadmium(II) ions from aqueous solutions by adsorption on activated carbon prepared from cashew nut shells. World Acad Sci Eng Technol 28:110-116

Temkin MI, Pyzhev V (1940) Kinetics of ammonia synthesis on promoted iron catalyst. Acta Physicochim URSS 12:327

Theivarasu C, Mylsamy S (2010) Equilibrium and kinetic adsorption studies of rhodamine-B from aqueous solutions using cocoa (Theobroma cacao) shell as a new adsorbent. Int J Eng Sci Technol 2:6284-6292

Trewyn GB, Slowing II, Giri S, Chen HT, Lin VSY (2007) Synthesis and functionalization of a mesoporous silica nanoparticle based on the sol-gel process and applications in controlled release. Acc Chem Res 40(9):846-853

Tzvetkova P, Nickolov R (2012) Modified and unmodified silica gel used for heavy metal ions removal from aqueous solutions. J Univ Chem Technol Metall 47:498-504

Vijayaraghavan K, Padmesh TVN, Palanivelu K, Velan M (2006) Biosorption of Ni(II) onto Sargassum wightii: application of twoparameter and three-parameter isotherm model. J Hazard Mater B133:304-308

Walcarius A, Etienne M, Lebeau B (2003) Rate of access to the binding sits in organically modified silicates. 2 . Ordered mesoporous silicas grafted with amine or thiol groups. Chem Mater 15:2161-2173

Walkarius A, Etienne M, Bessiere J (2002) Rate of access to the binding sites in organically modified silicates. 1. Amorphous silica gels grafted with amine or thiol groups. Chem Mater 14(6):2757-2766

Yantasee W, Lin Y, Fryxell GE, Busche BJ, Birnbaum J (2003) Removal of heavy metals from aqueous solution using novel nanoengineered sorbents: self-assembled carbamoylphosphonic acids on mesoporous silica. Sep Sci Technol 38(15):3809-3825

Zaporozhets O, Petruniock N, Bessarabova O, Sukhan V (1999) The removal of $\mathrm{Cu}(\mathrm{II})$ and $\mathrm{Zn}(\mathrm{II})$ using silica gel loaded with 1-(2-thiasolylazo)-2-naphthol. Talanta 49:899-906

Zhang L, Yu C, Zhao W, Chen H, Li L, Shi J (2007) Preparation of multi-amine grafted mesoporous silicas and their application to heavy metal ions adsorption. J Non-Cryst Solids 353(44-46):4055-4061

Zhu W, Wang J, Wu D, Li X, Luo Y, Han C, Ma W, He S (2017) Investigating the heavy metal adsorption of mesoporous silica materials prepared by microwave synthesis. Nanoscale Res Lett 12:323

Publisher's Note Springer Nature remains neutral with regard to jurisdictional claims in published maps and institutional affiliations. 